\title{
The Fabric of the Public in Debates About Gene Editing
}

\author{
Morgan Meyer \\ CSI-i3, Mines ParisTech, PSL, CNRS
}

\begin{abstract}
"Over the course of these past years and since the discovery of CRISPR-Cas9, there has been a broad consensus for the need to engage the public in the genome editing debate," the World Health Organization (WHO Expert Advisory Committee on Developing Global Standards for Governance and Oversight of Human Genome Editing, 2019, p. 28) writes in its background paper on the governance of gene editing. The WHO further notes that calls for public debate and dialogue have been made by a variety of stakeholders, including scientists, national academies, ethicists, as well as patients. Today, such a consideration for the public is not uncommon; some authors have observed that decisionmaking processes within institutions and governments have significantly opened through public engagement and that communication is now an "essential element of governance" (Irwin, 2010, p. 107). This new and more inclusive form of governance promotes an active and engaged role for the public, a public that is no longer perceived as ignorant or irrational but as an entity to be consulted.
\end{abstract}

These inclusive forms of governance are only one of many possible entanglements between technology and the public: many are convinced that the public should not be involved in decision making, and that scientific progress only needs to be "accepted." Others, still, imagine the possibility for members of the public to become active users of gene editing via do-it-yourself CRISPR kits and by collaborating with so-called "biohackers." This commentary scrutinizes and problematizes the different ways in which the public is imagined and positioned in debates about gene editing. I will argue that there is scope for analyzing the fabric of the public in more depth.

Gene editing has applications in domains ranging from health to the environment and agriculture. The technique has been considered to treat for instance HIV, Leber congenital amaurosis, sickle cell disorders, cystic fibrosis, and beta thalassemia. Frequently cited examples in agriculture include the creation of hornless cows, non-browning mushrooms and, more generally, of plants that are more resistant or that have improved nutritional qualities. Concerning environmental issues, gene editing can potentially be used to combat biodiversity loss and aid threatened species (i.e. birds), control invasive species (i.e. mice and rabbits), revive extinct species (i.e. mammoths), and control pests (by targeting insects and other disease vectors). While gene editing has implications in a number of fields, this article will focus above all on public debates in the field of agriculture.

\section{Kinds of public}

A first positioning of the public can be summarized as follows: the public must accept. Terms such as "public acceptance" and "consumer acceptance" are frequent in debates and academic publications. To take but one example, we read about people who need to be "informed of the benefits of genome editing-mediated plant breeding, trust in the relevant regulations" and that "careful risk-benefit communication" is necessary (Ishii \& Araki, 2016, p. 1507). The public is positioned here as a passive group and the perceived challenge is to educate, inform and convince the public of the positive features of gene editing. The prominence of the term "acceptance" amongst scientists and policymakers begs the question of why - despite controversies around GMOs, calls for "responsible" innovation, and criticisms of the deficit model - the public is still frequently portrayed as ignorant. 
A second way to position the public is to consider it as an actor that needs to be engaged with. For example, a French ethics committee stressed the "moral obligation" and the "duty" of public participation in its report on gene editing in plants (Comité consultatif commun d'éthique INRACIRADIFREMER, 2018, p. 26, 27). While the engagement with the public is portrayed as an obligatory passage point, the exact contours of this engagement remain unaddressed in the report. Furthermore, an active engagement of the public in deliberations on gene editing has been extremely rare to date. $A$ notable exception is the Norwegian Biotechnology Advisory Board that has engaged with the public between 2017 and 2018 when the Gene Technology Act was revised (Svingen, 2019). The public dialogue consisted of public debates, the submission of written contributions, as well as various conferences and meetings. But apart from such examples, a rethinking of public debates is called for: "governments and key stakeholders must design a new kind of engagement" (Burall, 2018, p. 438). The challenge here, as with public debates on science more generally, is at least twofold: how to enroll a representative group of people, and how to ensure that debates will have concrete impacts on policy making.

Third, members of the public can also become users of gene editing techniques. In 2016, a DIY CRISPR kit has been launched with the aim to democratize gene editing and make it available to nonprofessionals. In 2017, an event called CRISPR-kitchen was organized in Munich, Germany for which the DIY CRISPR kit was bought. The participants did, however, not use the kit as its use would have been considered illegal in Germany. Instead, the event was organized around discussions on ethical and governance issues, including a debate with the German regulator, as well as scenario- writing exercises (personal communication with a participant). Similarly, in 2018 a workshop was organized at the Open Wetlab of the Waag Society (Amsterdam, Netherlands) during which the DIY CRISPR kit was used and its ethical dimensions discussed. However, because appropriate permissions and supervision were not provided, the final step of the protocol was not realized (Joshy, 2018, pp. 31-32). At the moment of writing, the prospect of the wider public's use of gene editing remains hypothetical, in particular in Europe. In most community laboratories, CRISPR does not seem to be used (Kuiken, 2016). Instead, it is rather regarding public engagement, that DIY biology can play a significant role: "The DIY-biology community [...] should take part in a robust public dialogue about the use of CRISPR-Cas9 and how governance models can ensure safe, responsible research" (Kuiken, 2016, p. 168). Whether as participants in debates or users of technology, practitioners of DIY biology constitute a noteworthy public: a public shaped by the promises and imaginaries brought about by narratives of democratization and, at the same time, a public drawing attention to safety, ethics, and regulatory concerns.

Fourth, there is an approach that can be captured by the motto we need to know what the public knows and what it values. The public is seen as an entity that needs to be studied, understood and analyzed. For instance, some commentators (Rosemann et al., 2017) have called for comparative studies on public viewpoints, arguing that such studies are important in order to understand the attitudes, perceptions, values and preferences of people. MacDonald et al. (2020), in a paper published in this special issue, found that in New Zeeland the use of gene drives for biodiversity conservation has only a moderate level of support. A report mapping formal and informal public discussions in the UK shows that while "non-human Genome Editing is attracting significant attention from technical and policy experts, there are few indications of any substantial public discussion of the topic" (Smith \& Samuel, 2018, p. 3). Nevertheless, studies on public attitudes on gene editing have shown that citizens are not only interested in questions around technological risk, but that "they are also concerned with questions of the perceived benefits of a technology, trust in actors, equity and questions of bioethics" (Smith \& Samuel, 2018, p. 13). In a similar vein, NGOs seek to broaden debates on gene editing beyond technical aspects to also include political and societal implications (Helliwell et al., 2019). In contrast to the first approach of the public, which revolves around an assertion (the public must accept), the fourth approach revolves around a question: how does the public understand gene editing and what are its views on it?

Understanding what the public knows and what it values is, of course, a relevant question for the other positionings of the public discussed above. Those who construct the public as needing to "accept" 
gene editing can mobilize such understandings when arguing that the public does not know enough. On the contrary, those who actively engage with the public might mobilize such understandings for making, in the name of a knowledgeable public, recommendations for policy-makers. There are thus potential connections across these different types of public.

\section{How to study the fabric of the public?}

Debates about gene editing reveal multiple modes of existence of the public: as epistemic and economic accepters, as legitimized participants in debates and decision-making, as potential technology users, and as empirical research objects. Defining and problematizing the public in these different ways is not only a matter of academic categorization, such problematizations also engender different forms of politics and modes of governance and they have tangible effects on the social world. I would like to argue that a fertile research question is to further study the fabric of these different kinds of publics. The notion of "fabric" encourages us, on the one hand, to study the sites in which the public materializes. In which kinds of sites and spaces is the public being enacted, represented, framed and invited? On the other hand, the notion of fabric also refers to the idea of composition. What is the public composed of? What are the necessary ingredients to "weave" the public together? What kinds of motivations, concerns, devices, techniques, and discourses are necessary and/or mobilized in order to create a certain kind of public?

The study of the fabric of the public in debates on gene editing can build upon pragmatist-inspired analyses of the public (i.e. Marres, 2007). This means that the public should not be seen as something that preexists deliberation, but that it is actively produced and negotiated, and that it is co-produced by controversies. In order to understand the fabric of the public, we also need to think about the modalities of publicisation of gene editing. In other terms, the word public also needs to be understood as an adjective. The question is this one: how does gene editing become public? Through which kinds of devices is gene editing made a public object of concern? It is interesting here to contrast the debates around human gene editing to those around gene editing in agriculture. The former have received much attention: two international summits have been organized (in Washington in 2015 and in Hong Kong in 2018), a major controversy has erupted after the announcement by biologist $\mathrm{He}$ Jiankui of the birth of two gene-edited babies, and numerous press articles have covered the topic (Meyer, 2018). Various public events have been organized, ranging from panels at science festivals (see Rose et al., 2017) to public dialogues. Documentaries such as The CRISPR Revolution Genome Editing (2017), Human Nature (2019), Code of the Wild (2019) and Unnatural Selection (2019) have focused, above all, on human gene editing. Concerning agriculture, public debate has been much less important. There hasn't been any controversy comparable to that sparked by $\mathrm{He}$ Jiankui and international conferences on gene editing in agriculture (such as the one organized by the OECD in 2018 (OECD, 2018)) have not been as visible as the summits on human gene editing. Simply put, gene editing in agriculture is less public than human gene editing. A UK report observes that "non-human Genome Editing is a 'technical category' but not a 'public topic"' (Smith \& Samuel, 2018 , p. 3). Regarding environmental and ecological issues, this observation seems to be true as well: apart from media attention received by projects like the de-extinction of mammoths or the modification of mosquitos to prevent malaria, environmental applications of gene editing have not been very visible in the public.

\section{No(t) public: are gene edited organisms GMOs?}

Gene editing is often discussed in relation to GMOs. On the one hand, gene editing is portrayed as faster, safer, more precise and cheaper than traditional gene modification techniques. On the other, gene editing also reactivates past controversies around GMOs, something that many scientists and policy-makers are seeking to avoid. The use of gene editing in agriculture thus raises a key question: should gene edited organisms (GEOs) count as GMOs or not? While the US Department of Agriculture 
argued in 2018 that the answer is no, the European Court of Justice ruled the same year that the answer is yes. The question is particularly complex since it might be very difficult to differentiate GEOs from naturally-occurring mutations (and many argue that it is the final product and not the process that should be regulated). Unlike GMOs, which can be detected because they contain an insert from another organism, GEOs might be difficult or even impossible to detect. As a consequence, it is often argued that GEOs should not be regulated, that "GEOs' indistinguishability from nature should lead to their unaccountability in law" (Meyer \& Heimstädt, 2019, pp. 480-481).

The question of the equivalence between GEOs and GMOs is also a question that affects publics and consumers. In Europe, in order to be approved, GMOs have to be "safe," guarantee "freedom of choice" (for consumers, farmers, and business), be clearly labeled on food products, and be traceable. If GEOs are not regulated as GMOs, there will thus be no need to render them traceable and label them. For the public, i.e. the consumer, gene-edited organisms will become invisible. This invisibility of gene editing has been debated on various occasions, namely in the European parliament, where the problem of "hidden GMOs" was debated in March 2016 and in the German parliament during a debate on "invisible gene technology" in November 2019. For those in favor of classifying GEOs as GMOs, the argument is that gene editing is both a public issue and an issue for the public: gene edited organisms should be something public (i.e. made visible for consumers on products) and they should take into account the public (via regulations, policy debates, and public engagements). For those in favor of deregulating GEOs, the argument is the opposite: gene edited organisms do not have to be made public and they require no public. As we see, the legal status of gene editing is not simply a technical matter, but also a political and societal one. Even the specific terms used, such as "editing" and "new breeding techniques," have been criticized for being impenetrable and unrecognizable for the public (see Helliwell et al., 2019, pp. 785-786). The question, for social scientists and policymakers alike, is what kinds of publics and publicness do different types of regulation and denomination produce? Because regulation tends to be primarily discussed in terms of its scientific, technical, and economic dimensions, there is scope for broadening these debates to include the public into the equation as well.

This commentary has discussed four (ideal)types of publics in current debates on gene editing: epistemic/economic accepters, legitimized participants in debates and decision-making, technology users, empirical research objects. There are likely to be nuances and combinations of these types of publics that further academic work can uncover. This commentary has also proposed that we should further examine the fabric of the public. How and where does gene editing become a public issue and an issue for the public, and how and where is the public rendered invisible and irrelevant? This question can be empirically traced across various sites: academic publications, conferences, public reports, public debates, community laboratories, but also through regulation and consumption. While in some of these sites, the public might be imagined as a local or national entity, in others, the public might be imagined as a rather transnational and global entity. The question can also be contrasted across domains of application, such as health, agriculture, and the environment. The empirical question is not only to study the "weaving together" of the public, but also to situate - and compare and contrast - the fabric of the public across different sites and different locales.

\section{Acknowledgements}

The author would like to thank Quentin Dufour, Ingrid Metzler as well as Dominique Brossard and Dietram Scheufele for their insightful comments.

\section{Disclosure statement}

No potential conflict of interest. 


\section{References}

Burall, S. (2018) Rethink public engagement for gene editing. Nature, 555(7697), 438-439

Comité consultatif commun d'éthique INRA-CIRAD-IFREMER. (2018) Avis 11 sur les nouvelles techniques d'amélioration génétique des plantes

Helliwell, R., Hartley, S., \& Pearce, W. (2019) NGO perspectives on the social and ethical dimensions of plant genomeediting. Agriculture and Human Values, 36(4), 779-791

Irwin, A. (2010) Se confronter à l'engagement: discussion autour de trois perspectives critiques. Questions de Communication, 17(17), 107-128

Ishii, T., \& Araki, M. (2016) Consumer acceptance of food crops developed by genome editing. Plant Cell Reports, 35 (7), 1507-1518

Joshy, A. (2018) CRISPR ethics \& imagination: An evaluation of the role of DIY-CRISPR kit in Crispr-Cas9 deliberations [Master's thesis]. University of Twente

Kuiken, T. (2016) Governance: Learn from DIY biologists. Nature, 531(7593), 167-168

MacDonald, E. A., Balanovic, J., Edwards, E. D., Abrahamse, W., Frame, B., Greenaway, A., Kannemeyer, R., Kirk, N., Medvecky, F., Milfont, T. L., Russell, J. C., \& Tompkins, D. M. (2020) Public opinion towards gene drive as a pest control approach for biodiversity conservation and the association of underlying worldviews. Environmental Communication, 14(7), 904-918

Marres, N. (2007) The issues deserve more credit: Pragmatist contributions to the study of public involvement in controversy. Social Studies of Science, 37(5), 759-780

Meyer, M. (2018) “Irresponsible research? Dis/qualifying the gene editing of human embryos.” i3 Working Paper Series, 18-CSI-01

Meyer, M., \& Heimstädt, C. (2019) The divergent governance of gene editing in agriculture: A comparison of institutional reports from seven EU member states. Plant Biotechnology Reports, 13(5), 473-482

OECD. (2018, June 28-29) Conference on Genome Editing: Applications in Agriculture - Implications for Health, Environment and Regulation. OECD

Rose, K. M., Korzekwa, K., Brossard, D., Scheufele, D. A., \& Heisler, L. (2017) Engaging the public at a science festival: Findings from a panel on human gene editing. Science Communication, 39(2), 250-277

Rosemann, A., Zhang, X., \& Jiang, L. (2017) Human germ line gene editing: Why comparative, cross-national studies on public viewpoints are important. Anthropology, 05(1), 175

Smith, R. D., \& Samuel, G. (2018) Who's talking about non-human Genome editing? Mapping public discussion in the UK. Department of Business, Energy and Industrial Strategy

Svingen, M. (2019, September 4-7) Bringing the public to the editing table: Governance of new genome editing tools in Norway. Conference abstract, annual meeting of the society for the social studies of science, New Orleans

WHO Expert Advisory Committee on Developing Global Standards for Governance and Oversight of Human Genome Editing. (2019) Background paper governance 1. Human genome editing. World Health Organization

To cite this article: Meyer, Morgan (2020) The Fabric of the Public in Debates About Gene Editing, Environmental Communication, 14:7, 872-876

Link to this article: https://doi.org/10.1080/17524032.2020.1811477 